\title{
Contributos portugueses à teorização do jornalismo: das origens a 1974
}

Jorge Pedro Sousa

\section{Resumo}

Neste texto, procurar-se-ão resgatar alguns dos contributos portugueses à teorização do jornalismo, desde 1644 (primeira obra detectada, sobre verdade e jornalismo) até 1974, ano da Revolução que reinstituiu a democracia no país. Focalizaremos os seguintes temas: liberdade de imprensa, muitas vezes legalmente constrangida em Portugal; opinião pública; história do jornalismo; exercício do jornalismo; e ensino do jornalismo.

Palavras-chave:

Teoria do jornalismo, História do jornalismo, Portugal

\section{Portuguese contributions on theorizing journalism: from the beginnings to 1974}

Sobre o autor

Doutor e pós-doutor em Ciências da Informação pela Universidade de Santiago de Compostela e professor de Jornalismo na Universidade Fernando Pessoa (PortoPortugal). jorgepedrosousa@ hotmail.com

\section{Abstract}

In this work, we aim to present some of the Portuguese contributions to journalism theory, from 1644 (first work about truth and journalism) until 1974 (revolution and democracy). We will emphasize themes like: the freedom of the press, often legally constrained in Portugal; public opinion; the history of journalism; professional practice; and journalism teaching.

Key words:

Journalism theory, Journalism history, Portugal 
O jornalismo fez a sua aparição em Portugal no século XVII, merecendo especial destaque o surgimento da Gazeta "da Restauração" (1641-1647). O país acompanhava um movimento editorial jornalístico que transformava a Europa, ajudando a emancipar os cidadãos, sintonizando-os melhor com o seu entorno. Um fenómeno tão revolucionário e transformador como o da aparição das gazetas necessariamente provocou a atenção dos intelectuais da época. Cerca de um século e meio depois, em 1820, a Revolução Liberal permitiu, pela primeira vez, a instituição do princípio da liberdade de imprensa no país, o que gerou uma explosão do número de periódicos. No entanto, a democracia portuguesa estabelecida pela Constituição de 1822 foi sucessivamente abalada, até à Revolução de 25 de Abril de 1974, por vários períodos de ditadura e censura, sendo que o mais longo durou de 1926 a 1974. O jornalismo nacional ressentiu-se desse estado de coisas, mas com maiores ou menores dificuldades foi acompanhando a marcha dos tempos (Sousa, 2008: 93-118).

Apesar dos constrangimentos que sofreram, os estudiosos portugueses do jornalismo, motivados por razões académicas, profissionais ou mesmo políticas, não deixaram, também eles, de deixar uma marca nos estudos jornalísticos e contribuíram, a seu modo, para a formatação do campo científico, profissional e de conhecimento do jornalismo.

Em consonância com o exposto, este trabalho visa, com base em pesquisa bibliográfica e documental, realizada, principalmente, nas bibliotecas públicas portuguesas, e numa análise qualitativa das obras produzidas, descrever, com brevidade, o que escreveram alguns dos autores portugueses sobre vários dos principais temas que serviram de mote à teorização do jornalismo em Portugal, a saber: liberdade de imprensa, opinião pública, história do jornalismo, exercício do jornalismo e ensino do jornalismo.

\section{A génese da teorização do jornalismo em Portugal}

Cedo começou a preocupação nacional com o jornalismo, visto que logo em 1644 se encontra um texto em que Luís Marinho de Azevedo advoga criticamente a necessidade de verdade no jornalismo, contrapondo-a ao uso instrumental e propagandístico dos jornais. Nesse texto pioneiro, o autor chama também a atenção para um novo ofício, que acompanhava o surgimento dos jornais: o de gazeteiro. Aos gazeteiros, cobra-lhes o autor integridade e respeito pelos factos, exactamente como faz José Acúrcio das Neves (1808), mais de século e meio depois.

Entre 1820 e 1822, a Revolução Liberal e a consagração da liberdade formal de imprensa na ordem jurídica portuguesa detonou o aparecimento de periódicos políticos doutrinários. Duas correntes se desenharam, então: os conservadores, contrários à
Apesar dos constrangimentos que sofreram, os estudiosos portugueses do jornalismo, motivados por razões académicas, profissionais ou mesmo políticas, não deixaram, também eles, de deixar uma marca nos estudos jornalísticos e contribuíram, a seu modo, para a formatação do campo científico, profissional e de conhecimento do jornalismo 
liberdade de imprensa; e os liberais, favoráveis à mesma. Uma intensa discussão se abriu entre esses pólos, por intermédio de jornais e opúsculos. O campeão do campo conservador, José Agostinho de Macedo, por exemplo, publicou virulentos opúsculos contra a liberdade de imprensa, que via como adulteradora dos valores centrais da sociedade portuguesa e divisora da $\mathrm{Na}$ ção. Exorcismos Contra Periódicos e Outros Malefícios (1821) é, talvez, o folheto de Macedo de título mais sugestivo, mas noutros alcunha de "peste" os jornais (arma a que, paradoxalmente, ele próprio recorria). No pólo oposto, os liberais defendiam a liberdade de imprensa e a publicação de jornais como decorrentes do direito natural do homem à comunicação dos pensamentos e opiniões, como factores de progresso, de difusão de ideias e de conhecimentos, de acompanhamento dos actos políticos e de contenção do poder político, para não se cair novamente no despotis mo (Cavroé, 1821; Fernandes Tomás, 1821).

De qualquer modo, a teorização sobre liberdade de imprensa em Portugal, depois da intempestiva fase inicial do período 18201823, foi ultrapassando a crítica pessoal e panfletária para, gradualmente, ir assumindo contornos jurídicos e sociológicos. Teóricos como Carqueja (1893), Trindade Coelho (1897), Brochado (1960), Matos e Lemos (1964), Moura, Neves, Fernandes e Zenha (1968), Neves (1969), Azevedo (1969), Rego (1969; 1974), Borges Coutinho (1969), Araújo (1969), Carvalho e Cardoso (1971), Osório (1971), Vasconcelos (1972), Carvalho (1973) e Magalhães Godinho, (1971 e 1974), Silva e Sousa (1974), Ventura (1974) teceram considerações jurídicas e de outra natureza sobre os regimes legais da imprensa em Portugal e noutros países, procuraram definir, justificar ou criticar a liberdade de imprensa e a censura, historiografaram os regimes legais a que a imprensa foi sujeita em Portugal e ainda tentaram discutir as imposições jurídicas e as implicações sociais das sucessivas leis que regularam o jornalismo português. Em certos casos, a intenção "pedagógica" e descritiva é notória (Gonçalves, 1963); noutros casos, é essencialmente a preocupação com as consequências da censura que transparece. Por exemplo, França Borges (1900) e Silva (1968) defendem que a censura impede o público de conhecer acontecimentos relevantes. Entre todos esses trabalhos, talvez seja de destacar o livro de Alberto Arons de Carvalho e de Monteiro Cardoso (1971), intitulado Da Liberdade de Imprensa, pois trata-se de uma ampla (630 páginas!) exposição comparada e objectiva de diversos regimes jurídicos do jornalismo no mundo (democracias políticas; regimes socialistas; regimes autoritários), acompanhada pela descrição dos sistemas políticos que os sustentam. No livro, os autores defendem "a defesa do direito dos povos a serem informados e a discutirem livremente" (Carvalho e Cardoso, 1971: 9).
De qualquer modo,

a teorização sobre liberdade de imprensa em

Portugal, depois da intempestiva fase inicial do período 1820-1823, foi ultrapassando a crítica pessoal e panfletária para, gradualmente, ir assumindo contornos jurídicos e sociológicos 
José Júlio Gonçalves (1972) cruzou a historiografia com o direito e a sociologia para analisar a forma como o desenvolvimento da imprensa portuguesa foi constrangido pelos diferentes instrumentos jurídicos de regulação da actividade jornalística. Para ele, a censura trava o desenvolvimento do jornalismo, enquanto a liberdade de imprensa promove esse desenvolvimento.

Também do meio académico surgiu o livro de José Timóteo da Silva Bastos História da Censura Intelectual em Portugal, de 1926. Não se trata de uma obra sobre jornalismo, mas fala das entidades civis e religiosas que censuraram os jornais, situandose a meio caminho entre a teorização sobre liberdade de expressão e a história.

\section{Da teorização sobre liberdade de imprensa à teorização sobre opinião pública}

A reflexão sobre os efeitos sociais do jornalismo, em grande medida articulada com a discussão académica, política e ideológica sobre liberdade de imprensa, conduziu à teorização sobre opinião pública, realizada por autores como Carvalho (1940), Caetano (1965) e Barbosa (1968), este último especificamente sobre a interacção entre a Igreja e a opinião pública, por ocasião do Concílio Vaticano II. Entre eles merece particular destaque o trabalho académico do jurista e professor Marcelo Caetano, que três anos depois da publicação do livro se tornaria líder do último Governo da ditadura, vindo a ser derrubado pelo golpe de Estado de 25 de Abril de 1974.

Em A Opinião Pública no Estado Moderno, Marcelo Caetano defende que a opinião pública desempenha, desde o século XIX, uma função capital na política. Procurando defini-la, Marcelo Caetano recorda um político do século XIX que afirmava, caricaturalmente, que a opinião pública era a "opinião que se publica". No entanto, o autor avança com a sua própria definição:

a opinião pública é constituída pelos juízos compartilhados por grande número dos componentes de dado grupo social, de tal modo que um indivíduo ao exprimir algum desses juízos perante os seus concidadãos tenha considerável probabilidade de o não ver repelido, mas sim de encontrar um ambiente de receptividade e aprovação. Tratase de uma opinião, isto é, de um juízo individual; mas que é pública e, portanto, circula entre indivíduos num dado meio social de modo a tornar-se comum e até colectiva. (Caetano, 1965: 12).

Além disso, Caetano admite que a opinião pública deve ser considerada em relação a um grupo social e que podem coexistir várias correntes de opinião, pelo que "o indivíduo (...) passando de grupo em grupo, encontrará aqui receptividade para certo
O interesse de autores portugueses pela história do jornalismo, em particular pela história da imprensa, data do século XIX. Foi depois das duas últimas décadas do século XIX que se tornou constante o interesse pela história do jornalismo em Portugal 
juízo que acolá vê repelido" (Caetano, 1965: 13). Algumas opiniões circunscrevem-se ao indivíduo e não chegam ao estatuto de "públicas", diz o autor, mas outras obtêm a adesão de grupos sociais amplos podendo constituir-se como correntes de opinião dominantes.

Caetano (1965: 29) admite que "o processo ideal de formação da opinião pública consistiria em proporcionar a todos os indivíduos a mais ampla e circunstanciada documentação acerca (...) do seu tempo. Todo o cidadão deveria (...) ter livre acesso à informação". Porém, ainda de acordo com ele, a maior parte das pessoas não tem tempo para consumir mais do que alguma informação superficial, como acontece quando alguém folheia o jornal e se fica pela leitura dos títulos e de apenas uma ou outra notícia, mesmo assim nem sempre na totalidade. "Compreende-se, pois, o papel que a imprensa pode ter na formação das correntes superficiais e intermédias da opinião pública, não só através dos artigos e comentários que publica mas mediante a inserção, a disposição e a valorização do próprio noticiário" (Caetano, 1965: 30). Portanto, segundo Caetano, as influências sobre a produção de notícias, bem como a selecção e valorização de umas em relação a outras, retroactivamente afectam a formação de correntes de opinião: "Graças ao relevo dado a certo noticiário, a imprensa de informação pode provocar ondas de emoção ou despertar reacções (...) que agitem momentânea, mas por vezes violentamente, a opinião" (Caetano, 1965: 31). Por isso, Marcelo Caetano exige honestidade aos responsáveis pela produção e apresentação das notícias, por exemplo, a jornalistas e paginadores, até porque, prossegue, por vezes as notícias se fundam em boatos e rumores que envenenam "situações, atitudes e reputações" (Caetano, 1965: 33).

Segundo Caetano, o Estado moderno tem de agir não apenas como disciplinador da vida social e dador de segurança, mas também como empresário ou fiscal, entre outras funções. O autor afirma que "o Estado se tornou uma máquina tremendamente complexa e, por isso mesmo, cada vez mais pesada de conduzir e difícil de mover" (Caetano, 1965: 46). Uma das causas para isso, segundo Marcelo Caetano, é a opinião pública. Esta "aprova e condena actos e medidas" (Caetano, 1965: 49). Assim, Caetano explica que, num estado moderno, a opinião pública pode, em consequência, ter três funções: função motora, função refreadora e função sancionadora. Para ele, o Estado moderno não pode desprezar a opinião pública, "mas também lhe é impossível deixarse governar por ela.” (Caetano, 1965: 66) Sustenta a sua posição socorrendo-se do economista austríaco Schumpeter, que insistia no predomínio de factores irracionais na formação da opinião pública e considerava que os eleitores médios revelavam "falta do
A partir do final do século XIX, há várias orientações

no tratamento da história do jornalismo. Alguns autores publicam obras sobre a história

do jornalismo

português em geral, das quais a mais importante é a de Tengarrinha (1965).

Nela, Tengarrinha divide a história da imprensa portuguesa em três épocas: 1) Os primórdios da imprensa periódica em Portugal (até cerca de 1820);

2) A imprensa romântica ou de opinião ( 1820 em diante); 3)

A organização industrial da imprensa, marcada pela fundação do Diário de Notícias (1865; 1864 caso se considerem os números experimentais) 
sentido das realidades, enfraquecimento da noção de responsabilidade e ausência de espírito volitivo". Relembra, igualmente, Walter Lippman, que, de acordo com Marcelo Caetano, mostrou quanto "uma pequena minoria actuante, usando de processos publicitários e empregando atrevidas ousadias, pode, no meio da passividade geral, dar a ilusão de que se está perante uma corrente poderosa de opinião, onde não há mais que paixão ideológica, ambições audaciosas, interesses cúpidos ou então despeitos reivindicativos ou explosões de recalques." (Caetano, 1965: 66)

\section{A história do jornalismo}

O interesse de autores portugueses pela história do jornalismo, em particular pela história da imprensa, data do século XIX. O primeiro livro ilustrativo desse interesse data de 1857. Trata-se da obra Ensaios Sobre a História da Imprensa, escrita por Tito de Noronha, sobre a introdução e evolução da tipografia em Portugal. Nela, colateralmente, são apresentados dados sobre as primeiras folhas noticiosas ocasionais bem como sobre os primeiros jornais portugueses (onde foram impressos, quem os imprimiu, etc.).

José António Ismael Gracias (1880) desenvolveu o mesmo tipo de pesquisa, mas circunscrevendo-a à Índia Portuguesa, concretamente a Goa.

Foi depois das duas últimas décadas do século XIX que se tornou constante o interesse pela história do jornalismo em Portugal. Eduardo Coelho (1881) evocou o nascimento e desenvolvimento do jornalismo em Portugal numa comunicação apresentada ao Congresso Literário Internacional de Lisboa, tendo feito o mesmo em 1898 (Coelho, 1898), por ocasião da celebração, também na capital do país, do V Congresso Internacional da Imprensa, evento em que foi acompanhado, no tratamento do mesmo tema, por Alfredo da Cunha (1898), que 43 anos mais tarde publicaria uma importante história do jornalismo português até 1821 (Cunha, 1941a), na qual autores posteriores recolheram abundantes dados.

A partir do final do século XIX, há várias orientações no tratamento da história do jornalismo. Alguns autores publicam obras sobre a história do jornalismo português em geral, das quais a mais importante é a de Tengarrinha (1965). Nela, Tengarrinha divide a história da imprensa portuguesa em três épocas: 1) Os primórdios da imprensa periódica em Portugal (até cerca de 1820); 2) A imprensa romântica ou de opinião (1820 em diante); 3) A organização industrial da imprensa, marcada pela fundação do Diário de Notícias (1865; 1864 caso se considerem os números experimentais).

Outros autores debruçam-se sobre a imprensa e o jornalismo nas colónias ou em regiões e cidades do país (por exemplo: Gonçalves, 1964, 1965, 1966 e 1966/1967); outros ainda restringem-se à história do jornalismo especializado, nomeadamente nas áreas
As biografias, memórias e colectâneas de textos de jornalistas e ainda os elogios fúnebres

e discursos de homenagens constituem a maioria dos textos que se podem incluir nesta categoria de reflexão e pesquisa sobre jornalismo. Eles dão pistas para a compreensão do que se entendeu por "jornalismo" e por "jornalista" ao longo dos tempos, para a percepção dos valores profissionais e dos temas que

foram sendo discutidos no seio da classe e para 0 entendimento das rotinas produtivas em cada época histórica 
da medicina (por exemplo: Pina, 1945; Silva, 1974), do cinema (Costa, 1954) e da imprensa operária (Oliveira, 1973). Este último trabalho (Imprensa Operária no Portugal Oitocentista: 1825 - 1905, de César Oliveira) é particularmente interessante porque aborda temas sensíveis, como a imprensa socialista e anarquista e o respectivo discurso, numa época em que o regime ditatorial e corporativista censurava tudo o que pudesse soar a subversão.

Acham-se, igualmente, obras sobre a história de determinados jornais (por exemplo: Cunha, 1914; Carqueja, 1924; Carqueja, 1934), com especial destaque para o Diário de Notícias e $O$ Comércio do Porto. A obra de Jacinto Baptista (1966) é singularmente interessante por se tratar de uma profunda análise do discurso do número do jornal republicano $O$ Mundo de 5 de Outubro de 1910, data em que a República foi proclamada em Portugal. Existe, ainda, um livro sobre a história da imprensa brasileira elaborado por um autor português (Bessa, 1929).

A história das organizações jornalísticas e das personagens que nelas intervieram não foi esquecida pelos autores portugueses, sendo abordada por Luís Gomes (1925), Alfredo da Cunha (1941b) e por Boavida Portugal (1959), neste último caso restrita à Casa da Imprensa.

\section{Exercício do jornalismo}

As biografias, memórias e colectâneas de textos de jornalistas e ainda os elogios fúnebres e discursos de homenagens constituem a maioria dos textos que se podem incluir nesta categoria de reflexão e pesquisa sobre jornalismo. Eles dão pistas para a compreensão do que se entendeu por "jornalismo" e por "jornalista" ao longo dos tempos, para a percepção dos valores profissionais e dos temas que foram sendo discutidos no seio da classe e para o entendimento das rotinas produtivas em cada época histórica.

De uma forma geral, pode dizer-se que nos primeiros textos eram elogiadas as competências literárias e a capacidade retórica e persuasiva dos polemistas e políticos que por escreverem em jornais ou por os manterem se intitulavam jornalistas (por exemplo: Veloso, 1910-1911); um pouco mais tarde, as memórias de jornalistas acentuavam o espírito boémio e mundano, aventureiro e improvisador (o célebre "desenrascanço" português), mas também solidário, dos repórteres (por exemplo: Abreu, 1927; Bramão, 1936; Portela, 1943; Ferreira, 1945; Schwalbach, 1946; Amaral, 1949; Portela, 1956; Vieira, 1960); numa terceira fase, os textos começam a acentuar o profissionalismo jornalístico (Freire, 1936; Quadros, 1949). Embora vários valores profissionais sejam constantemente referidos em todas as épocas históricas (em especial, o apego à verdade, à liberdade e à integridade), observase, nesses livros, uma evolução no conceito de jornalista. O con-
Embora

vários valores

profissionais sejam

constantemente

referidos em todas

as épocas históricas

(em especial, 0

apego à verdade,

à liberdade e à integridade),

observa-se,

nesses livros,

uma evolução

no conceito

de jornalista.

O conceito de

jornalista como

polemista e literato

dá lugar ao conceito

do jornalista como

repórter boémio

e este dá lugar à

noção de jornalista

profissional 
ceito de jornalista como polemista e literato dá lugar ao conceito do jornalista como repórter boémio e este dá lugar à noção de jornalista profissional. Do mesmo modo, acompanhando um lento mas constante processo de profissionalização dos jornalistas portugueses, transparece dos livros uma mudança na concepção do jornalismo. Se primeiro o jornalismo é visto predominantemente como uma ocupação de "escritores de jornal" e polemistas, que usam as suas capacidades retóricas "inatas" para persuadir um reduzido número de leitores e que, frequentemente, nem sequer auferem qualquer remuneração, progressivamente o jornalismo passa a ser visto como profissão informativa, remunerada, auto-regulada por uma deontologia própria, onde se espelham os valores profissionais, e que exige competências profissionais específicas (como o domínio das técnicas da notícia, da entrevista e da reportagem em imprensa, rádio, televisão e cinema), que podem ser ensinadas e aprendidas. O jornalismo emerge, assim, finalmente, como arte liberal, ou profissão liberal.

Rodrigo Veloso (1910-1911), autor de seis mini-biografias de jornalistas políticos (mais propriamente "escritores de jornais" ou "cidadãos jornalistas") portugueses tardo-oitocentistas, dizia que o exercício do jornalismo exigiria ciência, talento, ilustração, conhecimentos sociológicos e políticos profundos, capacidade de observação desapaixonada, coragem, organização, independência e obediência exclusiva à voz da consciência, competência retórica e persuasiva. Aliás, Veloso (1911: 8-9) dividia os jornalistas entre os "jornaleiros", profissionais do jornalismo que auferiam salários, e os outros, os jornalistas do tipo dos seus biografados, que o autor tinha, certamente, em mais alta conta, por divulgarem "a boa doutrina, lições proveitosas para instrução e educação do povo" e verem o jornalismo como "sacerdócio". Esta ideia do jornalismo como sacerdócio, quase em oposição ao conceito de jornalismo como profissão, foi, sublinhe-se, recorrente na reflexão sobre jornalismo feita por jornalistas até meados do século XX.

Victor Falcão (1932: 202 e 206-207), na sua colectânea de crónicas intitulada Reflexões e Paradoxos, dizia que os jornalistas portugueses eram "maníacos" que trabalhavam sem terem "o direito de se queixar do menosprezo com que são tratados”. Denuncia, igualmente, o mercantilismo da imprensa e a cedência dos jornalistas às pressões dos proprietários dos jornais. Porém, assegura que nas redacções havia solidariedade.

João Paulo Freire (1934) fala da luta diária para manter um jornal com poucos recursos. Salienta, igualmente, que "não há em Portugal independência jornalística” pois para se criticar algo ou alguém é necessário ter dinheiro para se suportarem as consequências desses actos (Freire, 1934: 161), o que só se consegue, na versão do autor, com assinantes e vendas (Freire, 1934: 166). A “independência jornalística”, assegura João Paulo Freire (1934: 162),
Esta ideia do jornalismo como sacerdócio, quase em oposição ao conceito de jornalismo como profíssão, foi, sublinhe-se, recorrente na reflexão sobre jornalismo feita por jornalistas até meados do século $X X$ 
só existia no tempo em que os jornais representavam as vontades e os pensamentos de um único homem, como sucedeu no jornal Novidades, de Emídio Navarro. O valor da independência do jornalista também é vincado pelo mesmo autor num texto anterior (Freire, 1926), no qual narra os problemas com os "margalhos da censura".

Noutro texto, João Paulo Freire (1936: 27) via já o jornalismo como profissão liberal e desta a importância da função informativa dos jornais em detrimento da sua função opinativa ou mesmo polemista. Observa-se, assim, que efectivamente se deu uma transformação gradual na auto-imagem do jornalista português. O "profissional" da boémia, da aventura ou da polémica deu gradualmente lugar ao profissional da informação.

Fernanda Reis (1943: 7) considerava que os condicionalismos em que se exercia o jornalismo em Portugal levavam os jornalistas à apatia e à indiferença, matavam-lhes a imaginação e impediam que a imprensa tivesse uma verdadeira "utilidade pública".

Ao nível das rotinas profissionais, pode dizer-se que autores como Jorge de Abreu (1927), Bramão (1936) e Rafael Ferreira (1945) destacaram, essencialmente, nos seus livros de memórias e similares, a vida na redacção, onde o director, o chefe-de-redacção e o secretário-deredacção assumiam um papel fulcral; a capacidade de iniciativa individual de cada jornalista para obter a informação mais relevante em primeira-mão e bater a concorrência; e a capacidade de improviso, de recorrência aos mais diversos expedientes para conseguir exclusivos. A obtenção de informações relevantes em exclusivo era vista, tanto quanto ainda o é, como uma demonstração de competência e valor.

Os jornalistas que escreveram, em Portugal, sobre a sua vida jornalística também prestam abundantes testemunhos da solidariedade entre os membros da classe (Abreu, 1927; Bramão, 1936; Ferreira, 1945...). Transparecem, de facto, desses textos de memórias as cumplicidades dos membros da "tribo jornalística", como lhes chama Nelson Traquina (2004), unidos pela vida (boémia) que levavam, pela profissão comum e pelos valores profissionais (admiração pelas "cachas", respeito pela qualidade da expressão, apreço pela capacidade de socialização e convivência, sentido de missão...).

\section{Ensino do jornalismo}

Pelo menos desde 1898 que, por ocasião da realização, em Lisboa, do Congresso Internacional da Imprensa, que se debate em Portugal sobre a necessidade, ou não, dos cursos de jornalismo (Cunha, 1941 b; Freire, 1936; Quadros, 1949; Matos e Lemos, 1964). A reflexão produzida especificamente sobre o ensino do jornalismo, embora de pequena monta, é uma das facetas da teorização sobre jornalismo em Portugal antes de 1974. Ela circunscreve-se a duas grandes questões:

1) O jornalismo pode aprender-se? (Um jornalista "faz-se" ou "nasce feito"?)
Transparecem, de facto, desses

textos de memórias

as cumplicidades dos membros da

"tribo jornalística", como lhes chama Nelson Traquina (2004), unidos pela vida (boémia) que levavam, pela profíssão comum e pelos valores profissionais (admiração pelas "cachas", respeito pela qualidade da expressão, apreço pela capacidade de socialização e convivência, sentido de missão...) 
2) Faz sentido fundarem-se escolas de jornalismo? A serem fundadas, que tipo de escolas deverão ser instituídas e que tipo de cursos deverão possuir?

Como os autores que se debruçaram sobre essas questões eram, na generalidade dos casos, jornalistas feitos "na tarimba", tinham sido recrutados mais pela impressão subjectiva que causaram nos recrutadores do que pelas competências objectivas demonstradas (Sobreira, 2003: 147) e viviam num mundo em que o jornalismo era, frequentemente, visto como uma dimensão da literatura, pelo que as competências técnicas exigidas aos jornalistas se restringiam, essencialmente, aos dotes literários e à capacidade de escrever, a resposta às mesmas estava viciada à partida. Assim, em vários casos, certos autores defendem que o ensino do jornalismo não é necessário de todo. Bento Carqueja (cit. in Cunha, 1941 b: 30-31), por exemplo, dizia que "assim como não há escolas de poesia, também não as pode haver de formação de jornalistas". Para ele, como para outros jornalistas (Gastão, 1959), o bom exercício jornalismo não depende da formação académica, mas sim dos dotes de cada indivíduo.

Também Alberto Bramão (1899: 16) considera inútil instituir uma escola superior de jornalismo num país onde esta actividade não era vista como "verdadeira profissão". Outra razão avançada por Bramão para a não criação de um curso de jornalismo tem a ver com a impossibilidade de ensinar tão vasta matéria: "dentro do jornalismo cabe o universo inteiro", releva (Bramão, 1899:15). Além disso, para ele "a prova do valor jornalístico não pode ser tirada em exames (...). A prova do valor jornalístico só se verifica como a prova do valor guerreiro - no campo de batalha." (Bramão, 1899: 15). Segundo Alberto Bramão, não é, portanto, "com diplomas de bacharelato que os jornalistas podem autenticar as suas faculdades" (Bramão, 1899: 16). Pelo contrário, as virtudes de um jornalista, segundo Bramão (1899: 16), são o talento e o trabalho: "Já o disse um poeta (...): com talento e um caderno de papel, está um homem armado para a imortalidade."

Um outro autor que discorda da necessidade de ensino do jornalismo é Marques Gastão (1959). Em A Nobre Condição do Jornalista Diante da Literatura, o autor expressa a sua convicção de que os jornalistas comuns, mesmo quando ensinados, não chegam a ser autênticos, pois estes últimos teriam qualidades que os jornalistas comuns não possuem. O autor recorda Pulitzer, que defendia o ensino universitário do jornalismo mas que se questionava sobre se todas as condições necessárias para se ser jornalista podiam ser aprendidas, visto que várias delas tinham de ser qualidades inatas. "O jornalismo não é uma profissão que se aprende como as outras profissões, pois é preciso improvisar, arrojo e audácia”, escreve Marques Gastão. Para o autor, o jor-
A reflexão produzida especificamente sobre o ensino do jornalismo, embora de pequena monta, é uma das facetas da teorização sobre jornalismo em Portugal antes de 1974

\section{Estudos em Jornalismo e Mídia - Ano VI - n. 2 pp. 113 - 129 jul./dez. 2009}


nalista não pode ser uma pessoa indiferente ao que se passa à sua volta, "tem de ser dinâmico, extrovertido e apaixonado pelo que faz". Desta forma, "não se faz um jornalista como se faz um engenheiro ou doutor". Inclusivamente, o autor questiona: "se o jornalista autêntico tiver todos os requisitos de Pulitzer, para que precisa do ensino?" Marques Gastão relembra, igualmente, que há jornalistas que marcaram o seu lugar no mundo jornalístico sem o ensino universitário. Convictamente, diz que aqueles que estudam e desde cedo não mostram qualquer valor intrínseco para a profissão, irão falhar no futuro. Para o autor, apesar de existirem escolas de jornalismo na América e na Europa, o ensino não passaria de uma série de exercícios de redacção.

Para outros autores, como se intui da leitura do livro de João Paulo Freire (1936), o ensino do jornalismo é visto como podendo ser útil, mas não essencial. Alfredo da Cunha (1941 b: 34) tem a mesma leitura e diz que uma escola de jornalismo apenas pode adestrar competências pessoais. No entanto, este último autor admite que uma educação específica em jornalismo é conveniente, para que o exercício do jornalismo não seja um improviso. Já Luís de Quadros (1949) pugna não somente pela instituição de escolas de jornalismo mas também pela obrigatoriedade de uma formação específica em jornalismo para o exercício da profissão. Nuno Rosado (1966: 21) tem idêntica opinião: "a tendência é para a criação de escolas de jornalismo ao nível universitário", muito embora o autor admita que um jornalista também tenha, antes de mais, de saber expressar-se e de ser capaz de lidar com as mais diversas pessoas.

Não é de excluir que por trás das posições hiper-conservadoras e de resistência à mudança evidenciadas por autores como Bento Carqueja estivesse um certo receio dos jornalistas "instalados" e "feitos" nas redacções à hipótese destas serem "invadidas" por jornalistas formados em escolas específicas ou mesmo em universidades. Mário Matos Lemos (1964: 28-32 e 39), por exemplo, acusou os jornalistas da "velha guarda" de não quererem uma escola superior de jornalismo por estarem presos "às antigas concepções jornalísticas” e não terem qualquer preparação teórica que lhes permitisse "acompanhar o progresso". Para ele, seria "praticamente impossível explicar a muitos dos velhos profissionais que se nasce tanto jornalista como médico ou advogado. A prática é indispensável, mas o conhecimento teórico é (...) tão indispensável como aquela." (Matos e Lemos, 1964: 28) Mário Matos e Lemos, aliás, foi extremamente crítico para com os padrões de recrutamento de então, que privilegiavam quem "não quis ou não pode acabar o curso dos liceus ou superior. Surgem, assim, nas redacções um bom número de falhados que enveredam pelo jornalismo porque não sabem fazer mais nada do que escrever, geralmente
Não é de excluir que por trás das posições hiperconservadoras

e de resistência à mudança

evidenciadas por autores como Bento Carqueja estivesse um certo receio dos jornalistas "instalados"

e "feitos" nas redacções à hipótese destas serem "invadidas" por jornalistas formados em escolas específicas ou mesmo em universidades 
em mau português, e mais nada." (Matos e Lemos, 1964: 28) Este último ponto é relevante, pois os autores portugueses que reflectem sobre o ensino do jornalismo, mesmo quando admitem a existência de escolas e jornalismo, também manifestam dúvidas sobre os tipos de escola a fundar, os tipos de cursos a criar, em função dos possíveis destinatários e, em particular, sobre se o ensino do jornalismo deveria ter lugar nas universidades. Inclusivamente, autores como Freire (1936) faziam depender o curso a frequentar do tipo de jornalista que um indivíduo quereria ou poderia vir a ser no seio de uma classe extremamente estratificada, dividida, hierarquicamente, entre redactores, repórteres e informadores.

Mário Matos e Lemos (1964: 28-32) aborda, igualmente, um outro ponto correlacionado com o ensino do jornalismo. Para ele, seria quase uma perda de tempo mudar a legislação sobre a liberdade de imprensa em Portugal para a adequar ao princípio da responsabilidade social próprio das democracias ocidentais sem se alterar o regime de acesso ao exercício do jornalismo, o que começaria pela institucionalização de cursos superiores para a formação de jornalistas, de quatro ou cinco anos de duração e coroados por um estágio, à semelhança do que acontecia em "todos os países do mundo civilizado".

Costa Carvalho (1971: 8-10) afirma, por seu turno, que o jornalista "não se faz (...), nasce (...) para ser feito", pelo que defende a institucionalização do ensino do jornalismo, certo de que se a escola não faz tudo, pelo menos completa e orienta. O autor manifesta-se, também, bastante crítico para com as políticas de recrutamento dos jornalistas praticado pelas empresas portuguesas, que "descobrem os valores, recrutados ao acaso e com total confiança nos desígnios da Providência ou dos pedidos de intermediários das relações" (Costa Carvalho, 1971: 10).

Em conclusão, pode dizer-se que a reflexão sobre o ensino do jornalismo produzida em Portugal acompanhou não só o processo de gradual profissionalização dos jornalistas como também a tendência de se considerar o jornalismo uma profissão técnica passível de ser ensinada, como outras profissões liberais.

\section{Considerações finais}

Face aos dados encontrados, em síntese, talvez seja possível esboçar as seguintes considerações finais:

1) O jornalismo foi considerado um fenómeno social e cultural suficientemente relevante para merecer que vários autores, muitos deles engajados nessa estratégica actividade de comunicação social, o pensassem e discutissem. Teoriza-se sobre jornalismo em Portugal pelo menos desde o século XVII.

2) O pensamento jornalístico português teve origem na crítica à imprensa, na qual a discussão em torno do paradigma da verdade jornalística foi central. A partir, sensivelmente, do meio do

\footnotetext{
Estudos em Jornalismo e Mídia - Ano VI - n. 2 pp. 113 - 129 jul./dez. 2009
} 
século XIX o pensamento jornalístico português foi-se estendendo, gradualmente, a outras áreas, como a liberdade de imprensa, a ética e a deontologia do jornalismo, a história do jornalismo, o exercício do jornalismo, o ensino do jornalismo, etc.

3) Observa-se no pensamento jornalístico português desenvolvido até 1974 uma certa dificuldade em delimitar o território do jornalismo e em definir o conceito de jornalista. A título de exemplo, o jornalismo foi considerado, ou não, um ramo da literatura; foi visto como sendo uma ocupação ou, em alternativa, uma profissão; e foi entendido, por certos autores, como uma profissão passível de ser ensinada e aprendida, enquanto outros defendiam uma espécie de predestinação para o exercício da actividade jornalística.

\section{Notas}

Pesquisa apoiada pela Fundação para a Ciência e a Tecnologia, projecto PTDC/CCI-JOR/100266/2008.

\section{Referências}

ABREU, J. Boémia Jornalística. Memórias d'Um Profissional com 30 Anos de Serviço na "Fileira”. Lisboa: Livraria Editora Guimarães, 1927.

AMARAL, A. F. C. P. [também aparece como CABRAL, António]. As Minhas Memórias de Jornalista. Lisboa: Gráfica Santelmo, 1949.

ARAÚJO, A. C. Política do espírito: Asfixia da imprensa republicana no distrito de Viseu, in AUTORES VÁRIOS. II Congresso Republicano de Aveiro. Teses e Documentos. Textos Integrais. Volume II. Lisboa: Seara Nova, 1969.

AZEVEDO, L. M. Apologia militar en defensa de la victoria de Montijo contra las relaciones de Castilla, y Gazeta de Genoba, que la calumniaron mordaces, y la usurpan maliciosas. Lisboa: Imprensa de Lourenço de Anvers, 1644.

AZEVEDO, M. O jornal, o jornalista e a função formativa da imprensa, in AUTORES VÁRIOS. II Congresso Republicano de Aveiro. Teses e Documentos. Textos Integrais. Volume I. Lisboa: Seara Nova, 1969.

BARBosA, A. Relações Entre o Vaticano II e a Opinião Pública no Seu Tempo. Conferência Proferida no Seminário Maior do Porto no Encerramento da $1^{\text {a }}$ Exposição da Imprensa Diária Nacional em 19 de Maio de 1968. Braga: Oficina Gráfica do Diário do Minho. Separata da revista Theologica, vol. III, fasc. II, 1968.

BOAVIDA PORTUGAL, J. M. (1959). Para a História da Casa da Imprensa. Lisboa: Oficinas Gráficas da Gazeta dos Caminhos de Ferro, 1959.

BORGES COUTINHO, A. Breve comparação dos regimes jurídicos da imprensa em Portugal - Últimos dias da Monarquia, República, estado Novo, in AUTORES VÁRIOS. II Congresso Republicano de Aveiro. Teses e Documentos. Textos Integrais. Volume II. Lisboa: Seara Nova, 1969.

BRAMÃO, A. A. P. S. Recordações do Jornalismo, da Política, da Literatu- 
ra e do Mundanismo. Lisboa: Livraria Central Editora, 1936.

BRAMÃO, A. O Jornalismo. Lisboa: Tipografia Rua da Barroca, 1899.

BROCHADO, I. F. C. O Problema da Liberdade de Imprensa. Conferência Realizada no Porto em 19 de Fevereiro de 1960 Perante as Comissões Políticas da União Nacional do Distrito do Porto. Lisboa: Companhia Nacional Editora, 1960.

CAETANO, M. A Opinião Pública no Estado Moderno. Lisboa: Gráfica Manuel A. Pacheco, 1965.

CARQUEJA, B. A Liberdade de Imprensa. Porto: O Comércio do Porto, 1893.

CARqUEJA, B. O Comércio do Porto ao Completar Oitenta Anos. Notas para a Sua História. Porto: O Comércio do Porto, 1934.

CARquEJA, B. O Comércio do Porto ao Completar Setenta Anos. Notas para a Sua História. Porto: O Comércio do Porto, 1924.

CARVAlHO, A. A. A Censura e as Leis de Imprensa. Colecção “Que País?”, n. ${ }^{\circ}$ 3. Lisboa: Seara Nova, 1973.

CARVAlHO, A. A. e CARDOSO, A. M. (1971). Da Liberdade de Imprensa. Lisboa: Meridiano, 1971.

CARVAlHO, F. T. A Opinião Pública. Palestra Proferida ao Microfone da Emissora Nacional. Lisboa: Tipografia Empresa do Anuário Comercial, 1940 .

CAVRoÉ, P. A. Resposta ao Papel Intitulado Exorcismos Contra Periódicos e Outros Malefícios Com o Responso de Santo António Contra a Descoberta da Malignidade dos Aleijões Solapados. Lisboa: Imprensa Nacional, 1821.

COELHO, E. Le Portugal et Gutemberg. Quelques Indications Agrègées Sur le Dévelloppement de la Presse Portugaise Offertes Aux Membres du 5éme Congrès International de la Presse. Lisboa: Tipografia do Comércio, 1898.

COELHO, E. Notice Présentée au Congrès Littéraire International de Lisbonne, avec fac-simile de la Première Gazette Publiée en Portugal, offert au Congrès Littéraire International de Lisbonne, Lisboa: s/e, 1881.

COSTA CARVALHO. Jornalista, homem de carne e osso, in VIALE MOUTINHO, J. Imprensa, Informar ou Deformar? Porto: A. Ferreira, 1971.

COSTA, A. Breve História da Imprensa Cinematográfica em Portugal. Separata de Gazeta Literária, 11 - 18. Porto: Cine-club do Porto, 1954.

CUNHA, A. Elementos para a História da Imprensa Periódica Portuguesa (1641-1821). Separata das Memórias da Academia das Ciências de Lisboa, classe Letras, 4. Lisboa: Academia das Ciências de Lisboa, 1941 a.

CUNHA, A. Jornalismo Nacional: Das Malogradas Associações de Imprensa à Alvitrada Ordem dos Jornalistas Portugueses (Conferência 19291942). Lisboa: Tipografia Gráfica Santelmo, 1941 b.

CUNHA, A. La Presse Périodique en Portugal. Bref Mémoire Présenté au Cinquième Congrès International de la Presse, à Lisbonne. Comunicação ao V Congresso Internacional da Imprensa, Lisboa. Lisboa: Diário de Notícias, Setembro de 1898. 
CUNHA, A. O Diário de Notícias. A Sua Fundação e os Seus Fundadores. Lisboa: Tipografia Universal, 1914.

FALCÃO, V. Reflexões e Paradoxos. Lisboa: Gomes de Carvalho Editor, 1932.

FERNANDES TOMÁS, M. Resposta de João Carapuceiro, Compadre de Lisboa à Carta do Compadre de Belém Dirigidas ao "Astro da Lusitânia". Lisboa: Nova Imprensa da Viúva Neves e Filhos, 1821.

FERREIRA, R. Nos Bastidores do Jornalismo. Memórias de Rafael Ferreira. Lisboa: Romano Torres, 1945.

FRANÇA BORGES. A Imprensa em Portugal (Notas de um Jornalista). Porto: Tipografia a Vapor da Empresa Literária e Tipográfica, 1900.

FREIRE, J. P. Escolas de Jornalismo. Temas Profissionais. Porto: Livraria Educação Nacional, 1936.

FREIRE, J. P. Os Margalhos da Censura. Lisboa: Centro Tipográfico Colonial, 1926.

FREIRE, J. P. Pela República. Dois Anos de Luta ao Parapeito do "Diário da Noite". Lisboa: Livraria Central Editora, 1934.

GASTÃO, M. A Nobre Condição do Jornalista Diante da Literatura. Lisboa: s/e, 1959.

GOMES, L. F. Jornalistas do Porto e a Sua Associação. Porto: Associação de Jornalistas e Homens de Letras do Porto, 1925.

GONÇALVES, J. J. A Informação em Angola. Elementos para o Seu Estudo. Lisboa: s/e, 1964.

GONÇALVES, J. J. A Informação em Moçambique. Contribuição Para o Seu Estudo. Lisboa: Companhia Nacional Editora, 1965.

GONÇALVES, J. J. A Informação na Guiné, em Cabo Verde e em São Tomé e Príncipe. Separata do Curso de Extensão Universitária Cabo Verde, Guiné e São Tomé e Príncipe. Lisboa: ISCSPU, 1966.

GONÇALVES, J. J. A Informação nas Províncias do Oriente. Elementos para o Seu Estudo. Separata de Províncias Portuguesas do Oriente: Curso de Extensão Universitária (1966/67). Lisboa: Universidade Técnica de Lisboa/ISCSPU, 1966/1967.

GONÇALVES, J. J. Alguns Aspectos e Problemas da Evolução e Condicionamento da Imprensa em Portugal. Lisboa: Academia Internacional da Cultura Portuguesa. Separata do Boletim da Academia Internacional da Cultura Portuguesa, n. ${ }^{\circ}$ 5, 1972.

GRACIAS, J. A. I. A Imprensa em Goa nos Séculos XVI, XVII e XVIII. Apontamentos Histórico-Bibliográficos. Nova Goa: Imprensa Nacional, 1880.

MACEDO, J. A. Exorcismos Contra Periódicos e Outros Malefícios. Lisboa: Oficina da Viúva de Lino da Silva Godinho, 1821.

MAGALHÃES GODINHO, J. Liberdade de Imprensa. Conferência Proferida a 15 de Março de 1974. Porto: Ordem dos Advogados, 1974.

MAGALHÃES GODINHO, J. Lei de Imprensa. Crítica ao Projecto e Proposta Apresentados à Assembleia Nacional e Respectivos Textos. Lisboa: Edições Excelsior, 1971.

MATOS E LEMOS, M. Liberdade de Imprensa em Portugal. Mundo Novo 
e Universidade Portuguesa. Para a Formação da Europa. Lisboa: Edição do Autor, 1964.

MOURA, F. P.; NEVES, M.; FERNANDES, R. e ZENHA, S. O Estatuto da Imprensa. Debate. Lisboa: Prelo, 1968.

NEVES, J. A. Manifesto da Razão Contra as Usurpações Francesas Oferecido à Nação Portuguesa, aos Soberanos e aos Povos. Lisboa: Oficina de Simão Tadeu Ferreira, 1808.

NEVES, N. T. Liberdade de Imprensa e Dignificação da Palaura. Porto: Edição do autor, 1969.

NORONHA, T. Ensaios Sobre a História da Imprensa. Lisboa: Tipografia Franco-Portuguesa de Lallemant \& $\mathrm{C}^{\mathrm{a}}, 1857$.

OLIVEIRA, C. Imprensa Operária no Portugal Oitocentista (1825-1905). Separata Análise Social, n. ${ }^{\circ}$ 39, 1973.

OSÓRIO, R. Temas para diálogo, in VIALE MOUTINHO, J. Imprensa, Informar ou Deformar? Porto: A. Ferreira, 1971.

PINA, L. Isagoje Histórica do Jornalismo Médico. Separata do Jornal do Médico, n. ${ }^{\circ}$ 5. Porto: Costa Carregal, 1945.

PORTELA, A. Os Mortos Falam. Lisboa: Inquérito, 1943.

PORTELA, A. Reinaldo Ferreira (Repórter X). Memórias de um Ex-Morfinómamo. Lisboa: Tipografia Companhia Nacional Editora, 1956.

QUADROS, L. Falta Uma Escola de Jornalismo em Portugal?. Lisboa: Tipografia Oficinas Gráficas, 1949.

REGO, R. A censura prévia administrativa, in AUTORES VÁRIOS. II Congresso Republicano de Aveiro. Teses e Documentos. Textos Integrais. Volume I. Lisboa: Seara Nova, 1969.

REGO, R. Da censura prévia ao exame prévio, in AUTORES VÁRIOS. $3^{\circ}$ Congresso da Oposição Democrática de Aveiro. Teses. $7^{\mathrm{a}}$ Secção. Lisboa: Seara Nova, 1974.

REIS, F. O Jornalismo Colonial na Metrópole. Separata do Boletim Geral das Colónias, n. ${ }^{\circ} 220$. Lisboa: Agência Geral das Colónias, 1943.

ROSADO. N. A Imprensa. Lisboa: Ministério da Educação Nacional/Direcção-Geral do Ensino Primário, 1966.

SCHWALBACH, E. À Lareira do Passado: Memórias. Lisboa: Edição do autor, 1946.

SILVA BASTOS, J. T. História da Censura Intelectual em Portugal. Ensaio Sobre a Compreensão do Pensamento Português. Coimbra: Imprensa da Universidade de Coimbra, 1926.

SILVA E SOUSA, A. Liberdade de expressão, reunião e associação, in AUTORES VÁRIOS. $3^{\circ}$ Congresso da Oposição Democrática de Aveiro. Teses. $7^{a}$ Seç̧ão. Lisboa: Seara Nova, 1974.

SILVA, A. A. C. C. Subsídios para a História da Imprensa Farmacêutica Portuguesa. Separata do Boletim da Faculdade de Farmácia, n. ${ }^{\circ} 34$. Coimbra: Faculdade de Farmácia, 1974.

SILVA, R. A Censura: Consequências Marginais. Luanda: Neográfica, 1968 .

SOBREIRA, R. M. Os Jornalistas Portugueses 1933-1974. Uma Profissão 
em Construção. Lisboa: Livros Horizonte, 2003.

SOUSA, J. P. Uma história do jornalismo em Portugal até ao 25 de Abril de 1974, in SOUSA, J. P. (Org.). Jornalismo: História, Teoria e Metodologia da Pesquisa. Porto: Edições Universidade Fernando Pessoa, pp. 93-118.

TENGARRINHA, J. História da Imprensa Periódica Portuguesa. Lisboa: Portugália, 1965.

TRAQUINA, N. A Tribo Jornalística. Lisboa: Livros Horizonte, 2004.

TRINDADE COELHO, J. F. (1897). Liberdade de Imprensa. Proposições Apresentadas ao Congresso da União Internacional de Direito Penal. Lisboa: Antiga Casa Bertrand-José Bastos.

VASCONCELOS, J. C. (1972). Liberdade de Imprensa. Lei de Imprensa. Lisboa: Prelo, 1972.

VELOSO, R. Jornalistas Portugueses. 6 volumes. Famalicão: Tipografia Minerva, 1910/1911.

VENTURA, M. A censura como arma de repressão política, in AUTORES VÁRIOS. $3^{\circ}$ Congresso da Oposição Democrática de Aveiro. Teses. $7^{\mathrm{a}}$ Secção. Lisboa: Seara Nova, 1974.

VIALE MOUTINHO, J. (Coord.) Imprensa: Deformar ou Informar? Porto: A. Ferreira, 1971.

VIEIRA, A. T. Memórias de um Repórter. Lisboa: s/e, 1960.

Recebido em 17 de setembro de 2009 Aprovado em 1 de outubro de 2009 